\title{
A cloud filtering method for microwave upper tropospheric humidity measurements
}

\author{
S. A. Buehler ${ }^{1}$, M. Kuvatov ${ }^{2}$, T. R. Sreerekha ${ }^{3}$, V. O. John ${ }^{4}$, B. Rydberg ${ }^{5}$, P. Eriksson ${ }^{5}$, and J. Notholt ${ }^{2}$ \\ ${ }^{1}$ Lulea Technical University, Dept. of Space Science, Kiruna, Sweden \\ ${ }^{2}$ IUP, University of Bremen, Bremen, Germany \\ ${ }^{3}$ Satellite Applications, Met Office, Exeter, UK \\ ${ }^{4}$ RSMAS, University of Miami, USA \\ ${ }^{5}$ Dept. of Radio and Space Science, Chalmers University of Technology, Gothenburg, Sweden
}

Received: 14 March 2007 - Published in Atmos. Chem. Phys. Discuss.: 30 May 2007

Revised: 19 October 2007 - Accepted: 19 October 2007 - Published: 5 November 2007

Abstract. The paper presents a cloud filtering method for upper tropospheric humidity (UTH) measurements at $183.31 \pm 1.00 \mathrm{GHz}$. The method uses two criteria: a viewing angle dependent threshold on the brightness temperature at $183.31 \pm 1.00 \mathrm{GHz}$, and a threshold on the brightness temperature difference between another channel and $183.31 \pm 1.00 \mathrm{GHz}$. Two different alternatives, using $183.31 \pm 3.00 \mathrm{GHz}$ or $183.31 \pm 7.00 \mathrm{GHz}$ as the other channel, are studied. The robustness of this cloud filtering method is demonstrated by a mid-latitudes winter case study.

The paper then studies different biases on UTH climatologies. Clouds are associated with high humidity, therefore the possible dry bias introduced by cloud filtering is discussed and compared to the wet biases introduced by the clouds radiative effect if no filtering is done. This is done by means of a case study, and by means of a stochastic cloud database with representative statistics for midlatitude conditions.

Both studied filter alternatives perform nearly equally well, but the alternative using $183.31 \pm 3.00 \mathrm{GHz}$ as other channel is preferable, because that channel is less likely to see the Earth's surface than the one at $183.31 \pm 7.00 \mathrm{GHz}$.

The consistent result of all case studies and for both filter alternatives is that both cloud wet bias and cloud filtering dry bias are modest for microwave data. The recommended strategy is to use the cloud filtered data as an estimate for the true all-sky UTH value, but retain the unfiltered data to have an estimate of the cloud induced uncertainty.

The focus of the paper is on midlatitude data, since atmospheric data to test the filter for that case were readily available. The filter is expected to be applicable also to subtropical and tropical data, but should be further validated with case studies similar to the one presented here for those cases.

Correspondence to: S. A. Buehler

(sbuehler@ltu.se)

\section{Introduction}

Humidity in the atmosphere, and particularly in the upper troposphere, is one of the major factors in our climate system. Changes in its distribution affect the atmospheric energy balance. It is therefore essential to monitor and study upper tropospheric humidity (UTH), and to make such data available to the scientific community. In contrast to traditional direct measurements of atmospheric humidity by radiosondes, satellites provide humidity measurements with global coverage. Satellite measurements of UTH are typically made in two specific frequency regions: in the infrared at $6.3 \mu \mathrm{m}$ and in the microwave at $183.31 \mathrm{GHz}$. The infrared instruments are the more established ones, whereas the microwave instruments became available only rather recently.

These infrared and microwave instruments passively measure thermal radiation emitted by the atmosphere and the Earth's surface. The radiances, which have the physical unit Watt per square meter, Hertz, and steradian, are measured by a receiver, which is calibrated in terms of brightness temperature $\left(T_{B}\right)$ in Kelvin. In this article we will use the terms radiances and brightness temperature more or less as synonyms, with the distinction of the different units.

More strictly speaking, the instruments do not measure the real brightness temperature directly, but the antenna temperature, which must be bias corrected and antenna pattern corrected. The microwave data used in this article were calibrated to brightness temperature with the AAPP software package, which applies these corrections. (For details on AAPP and the corrections applied see Labrot et al. (2006).)

UTH can be retrieved from satellite radiances using an algorithm developed by Soden and Bretherton (1996). They used a linear relation between the natural logarithm of UTH and brightness temperature $\left(\ln (\mathrm{UTH})=a+b * T_{B}\right)$, and derived the fit parameters $a$ and $b$ using linear regression. In

Published by Copernicus Publications on behalf of the European Geosciences Union. 
this algorithm, UTH is defined as the Jacobian weighted mean of relative humidity in the upper troposphere which is roughly between 500 and $200 \mathrm{hPa}$. (It should be noted that the Jacobian based UTH definition means that the UTH product can not be associated with a fixed altitude or pressure range, but moves slightly up and down for different atmospheric conditions. This reflects the physics of the measurement. No attempt to correct for it is made, in order to keep the product as free as possible from biases.) Soden and Bretherton (1996) applied the algorithm to infrared data from the HIRS instrument.

One of the available microwave instruments for measuring UTH is the Advanced Microwave Sounding Unit B (AMSUB) (Saunders et al., 1995). It has three humidity sounding channels centered around a water vapor absorption line at $183.31 \mathrm{GHz}$. These channels have center frequencies of $183.31 \pm 1.00,183.31 \pm 3.00$, and $183.31 \pm 7.00 \mathrm{GHz}$ and will be referred to as Ch18, Ch19, and Ch20, respectively. Recently, Buehler and John (2005) demonstrated that UTH can be derived from AMSU-B Ch18 brightness temperatures with a precision of $2 \% \mathrm{RH}$ at low UTH values and $7 \% \mathrm{RH}$ at high UTH values. The same retrieval algorithm was used for the work described here. We will refer to the above paper as BJ. BJ gives scaling coefficients for UTH retrieval in two different humidity units, relative humidity over liquid water and relative humidity over ice. We use the former here, and limit the value range to below $100 \% \mathrm{RH}$, since higher values relative to liquid water are not physical.

In general, clouds are more transparent in the microwave than in the infrared. Therefore, data from microwave sensors are less contaminated by clouds than data from IR sensors. This is particularly true for Ch18 of AMSU-B. The signal it receives originates mostly from the upper part of the troposphere. Thus, it is not sensitive to low clouds. However, clouds can affect the measurement if there is a high cloud with a high ice content in the line of sight (LOS) of the instrument. In such a case the radiation is scattered away from the LOS by ice particles in the cloud so that the brightness temperature measured by the instrument is colder than it would be without the cloud.

In clear-sky conditions, brightness temperatures from Ch18 $\left(T_{B}^{18}\right)$ are colder than brightness temperatures from $\mathrm{Ch} 20\left(T_{B}^{20}\right)$. This is due to the atmospheric temperature lapse rate, and the fact that $\mathrm{Ch} 18$ is sensitive to a higher region of the troposphere than $\mathrm{Ch} 20$. However, in the presence of ice clouds $T_{B}^{18}$ can be warmer than $T_{B}^{20}$. Thus, the brightness temperature difference, defined as $\Delta T_{B}(20)=T_{B}^{20}-T_{B}^{18}$ can be used to detect the presence of clouds. For example, Adler et al. (1990) showed, using aircraft microwave observations, that $\Delta T_{B}(20)$ can reach down to $-100 \mathrm{~K}$ in a strong convective system and Burns et al. (1997) suggested to use $\Delta T_{B}(20)<0$ as a criterion to filter out convective cloud cases before retrieving water vapor from these measurements.
The same argument applies to the pair Ch18 and Ch19, since the sounding altitude of $\mathrm{Ch} 19$ is between that of $\mathrm{Ch} 18$ and that of Ch20. The difference $\Delta T_{B}(19)=T_{B}^{19}-T_{B}^{18}$ thus also should be applicable for cloud filtering.

Greenwald and Christopher (2002) investigated the effect of cold clouds (defined as $11 \mu \mathrm{m}$ brightness temperatures less than $240 \mathrm{~K}$ ) on $T_{B}^{18}$. They concluded that nonprecipitating clouds produce on average $5 \% \mathrm{RH}$ error in UTH retrieval, whereas precipitating clouds produce $18 \% \mathrm{RH}$ error. They used infrared data to estimate the clear-sky background $T_{B}^{18}$ (which was found to be $242 \pm 2 \mathrm{~K}$ ) in order to estimate this error. Unfortunately, it is not possible to use the above numbers directly to assess the impact of clouds on a UTH climatology, because the averages refer not to the total number of measurements, but only to all clouds in the given class, where the class definitions are somewhat arbitrary. For example, if the non-precipitating cloud class is extended towards thinner clouds, then the average impact of clouds of this class on UTH will appear to be smaller.

Another application of AMSU-B data cloud filtering is given by Hong et al. (2005). The authors used the three AMSU-B sounding channels centered around $183.3 \mathrm{GHz}$ to detect tropical deep convective clouds. They conclude that the deep convective cloud fraction in the tropics is around $0.3 \%$, and that the contribution of overshooting convection to this is around $26 \%$.

In this article we develop a cloud filter that uses only the microwave data, no additional infrared data (Sect. 2). This is achieved by combining the approaches from earlier studies. We use a case study to demonstrate the robustness of the filter (Sect. 3.1). Next, we use the same case study to estimate the bias in the retrieved UTH that is introduced by the cloud filtering, and compare that to the bias introduced by the radiative effect of the clouds themselves, if they are not filtered out (Sect. 3.2). In this context, the impact of surface emissions on retrieved UTH and on the cloud filtering procedure must also be discussed (Sect. 3.3). Finally, we put the results from the case study on a firmer statistical basis by analyzing the cloud bias and cloud filtering bias for a stochastic dataset of midlatitude cloud cases with realistic statistics (Sect. 3.4). Section 4 contains a summary and the conclusions of this work.

\section{Cloud filter methodology}

We studied two different cloud filters. The first combines a threshold on $T_{B}^{18}$ with a threshold on $\Delta T_{B}(20)$, the second combines a threshold on $T_{B}^{18}$ with a threshold on $\Delta T_{B}(19)$. Both filters use the same threshold values of $T_{B}^{18}(240.1 \mathrm{~K}$ for nadir data). For brevity, we will refer to the two different filters as Ch20 filter and Ch19 filter, respectively, but it is important to keep in mind that both filters also include the $T_{B}^{18}$ threshold. 

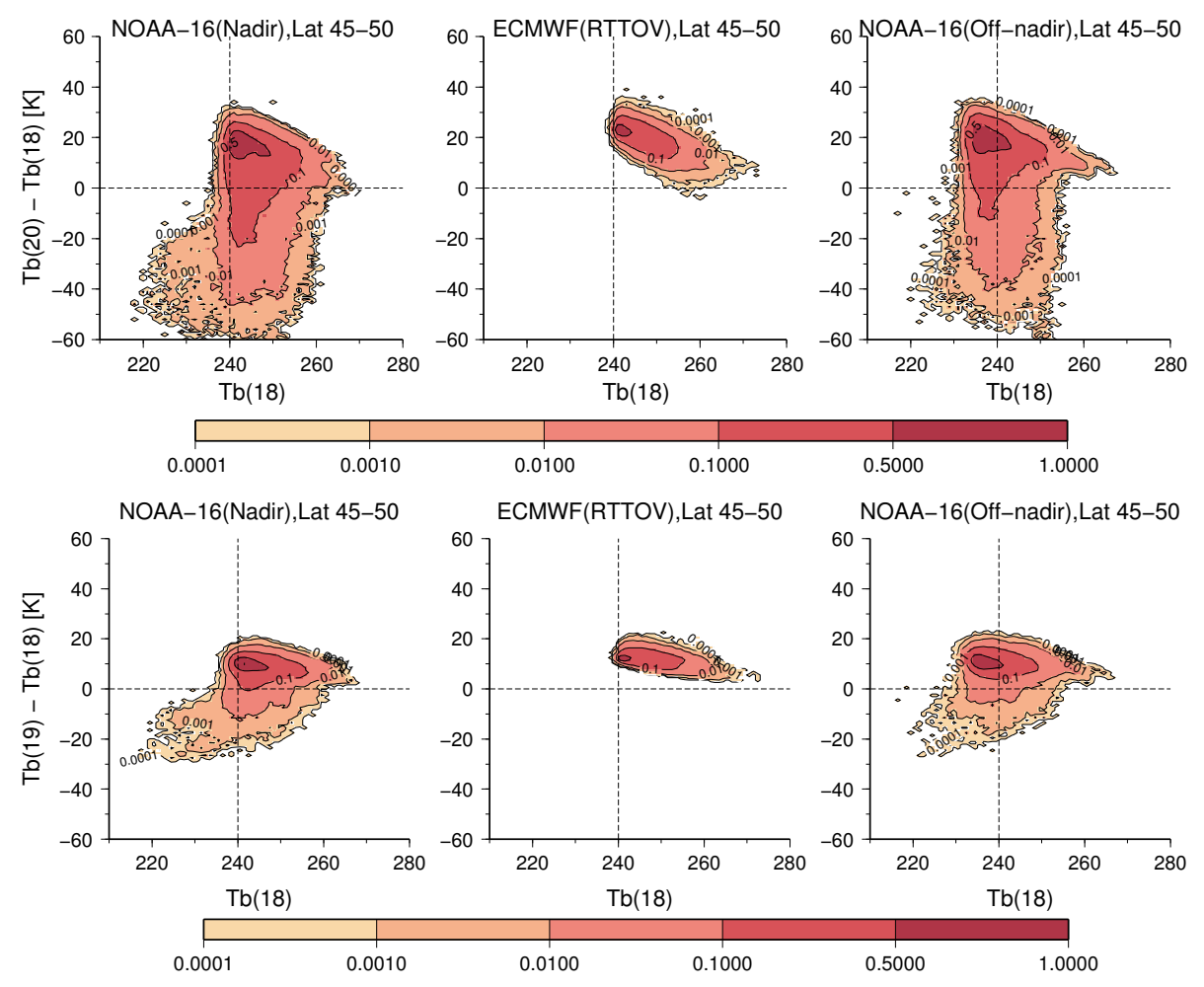

Fig. 1. Top row, left plot: combined histogram of the measured difference between AMSU-B Ch20 and 18 brightness temperatures $\left(\Delta T_{B}(20)\right.$, y-axis) and Ch18 brightness temperature (x-axis). Fields of view (FOVs) used were the five innermost FOVs on both sides from nadir, with FOV numbers 41-50. Top row, middle plot: RTTOV simulation of clear-sky brightness temperatures from ECMWF data. The data are for January 2004, near nadir viewing geometry, and a 45-50 latitude band. Top row, right plot: the same as on the left, but for off-nadir looking measurements. FOVs used were the five outermost FOVs on both edges of the scanline, with FOV numbers 1-5 and 86-90. Bottom row: Same as top row, but for $\Delta T_{B}(19)$ instead of $\Delta T_{B}(20)$.

To demonstrate these filters, we use two-dimensional histograms of $\Delta T_{B}$ versus $T_{B}^{18}$, such as the ones shown in Fig. 1. In the top left plot, one month of AMSU-B measurements were used to plot the histogram. The color coded contour levels show the frequency of measurements, normalized relative to the maximum. In other words, the figure shows the combined probability density function (PDF) for $T_{B}^{18}$ and $\Delta T_{B}(20)$. The maximum of the PDF is near $T_{B}^{18}=245 \mathrm{~K}$ and $\Delta T_{B}(20)=20 \mathrm{~K}$. Most cases are indeed above $T_{B}^{18}=240 \mathrm{~K}$ and $\Delta T_{B}(20)=0 \mathrm{~K}$. There is a tail of cases with negative $\Delta T_{B}(20)$ as low as $-60 \mathrm{~K}$. We identify these cases mostly with clouds. The bottom left plot of Fig. 1 shows the same as the top left plot, but for $\Delta T_{B}(19)$ instead of $\Delta T_{B}(20)$. The plots demonstrate that the method can work in this case as well. The remaining sub plots of Fig. 1 will be explained later.

In principle, negative $\Delta T_{B}$ values can also be an indicator of surface influence on $T_{B}^{18}$. Under very dry atmospheric conditions, both channels measure radiation emitted from the Earth's surface and the atmosphere. If we assume the surface emissivity to be the same for both channels, $T_{B}^{18}$ will be warmer than $T_{B}^{20}$ because the contribution of atmospheric emission will be more for $\mathrm{Ch} 18$ as the frequencies are closer to the line center.
Figure 2 illustrates this. Its top plot shows how the brightness temperature of different AMSU-B channels changes with changing total water vapor column (TWV). The basic atmospheric state was the midlatitude-winter case of Anderson et al. (1986). The humidity profile was scaled to get different TWV values. Shown are simulations for two extreme cases of surface emissivity, 0.95 and 0.60 , which represent the likely range for this parameter. We define the threshold for surface influence as the TWV value where the curves for the different emissivity extremes separate. Ch18 has surface influence for TWV below approximately $3 \mathrm{~kg} / \mathrm{m}^{3}$.

The bottom plot of Fig. 2 shows brightness temperature differences as a function of TWV. The $\Delta T_{B}(19)$ becomes negative at TWV below approximately $3 \mathrm{~kg} / \mathrm{m}^{3}$, so it is a good filter against surface influence. The $\Delta T_{B}(20)$ already becomes negative at TWV below approximately $7 \mathrm{~kg} / \mathrm{m}^{3}$. Thus, the Ch20 filter removes some data for which $\mathrm{Ch} 18$ is still unaffected by the surface.

The threshold value of $3 \mathrm{~kg} / \mathrm{m}^{3}$ for both surface influence on Ch18 and sign-change in $\Delta T_{B}(19)$ is valid also for other atmospheric conditions, which was verified by making plots (not shown) similar to Fig. 2 for the other scenarios of Anderson et al. (1986) (tropical, midlatitude-summer, etc.). 

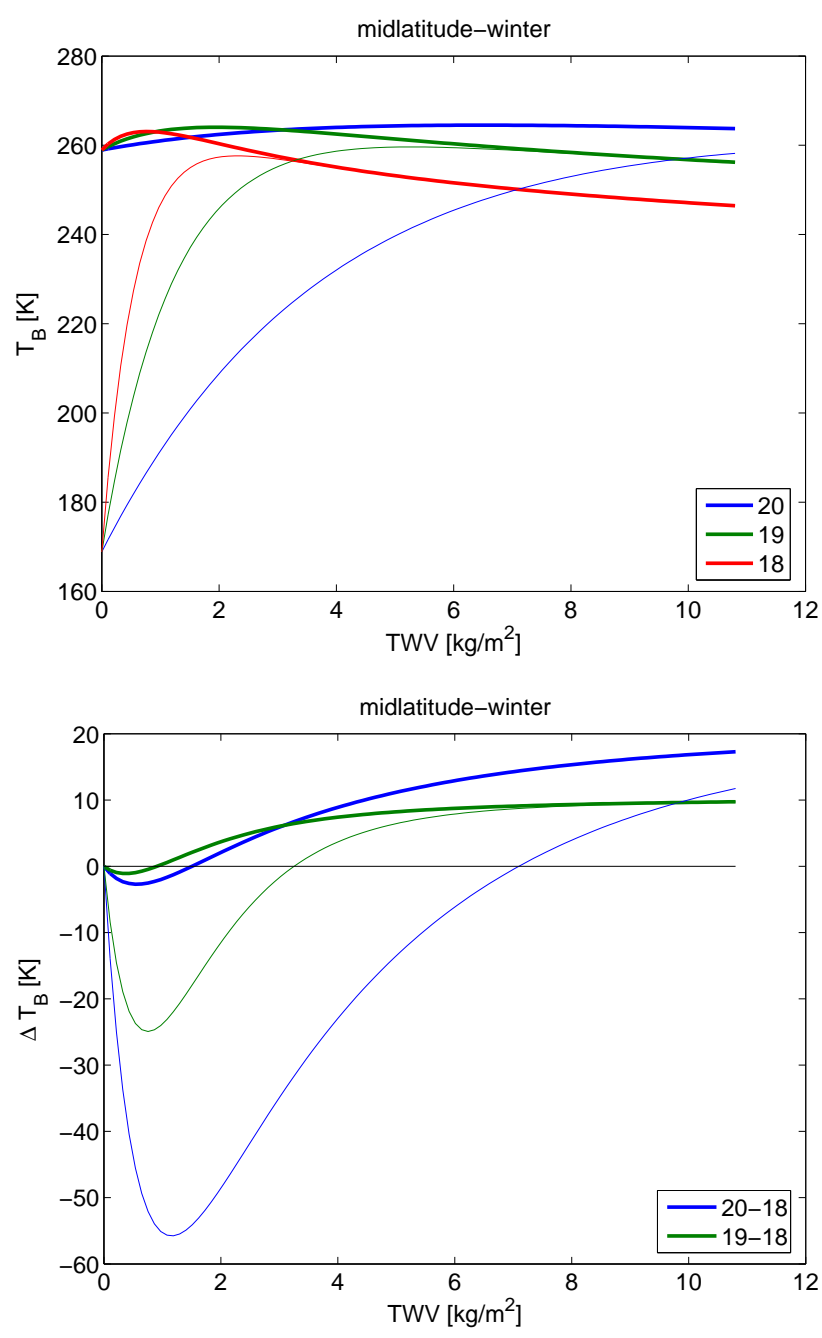

Fig. 2. Surface influence on AMSU-B channels 18-20 for a midlatitude-winter atmosphere. Top: Brightness temperature for the three different channels as a function of total water vapor column (TWV). The thick lines are for emissivity 0.95 , the thin lines for emissivity 0.60. Bottom: Brightness temperature differences $\left(\Delta T_{B}(20)\right.$ and $\left.\Delta T_{B}(19)\right)$. As in the top plot, line thickness indicates the two different emissivity cases.

To validate the assumption that negative $\Delta T_{B}$ values for not too dry atmospheres are caused by clouds, a twodimensional histogram was plotted with brightness temperatures simulated for a clear-sky scenario (not considering clouds in the radiative transfer (RT) model). The result of this exercise is demonstrated in the top middle and bottom middle plots of Fig. 1. The top plot is for the Ch20 filter, the bottom plot for the Ch19 filter. The brightness temperatures used in this figure are calculated with the RT model RTTOV-7 (Saunders, 2002) using ECMWF ERA-40 reanalysis data. The surface emissivity model was FASTEM (English and Hewison, 1998) over the ocean, and one of five different fixed surface emissivity values, depending on terrain type, over land. Con- firming our expectations, this figure shows that for clear-sky conditions there are very little data where $\Delta T_{B}$ (both 20 and 19 ) is below $0 \mathrm{~K}$. The simulated clear-sky data also confirms the criterion of Greenwald and Christopher (2002) that $T_{B}^{18}$ should be above $240 \mathrm{~K}$ for clear-sky cases, which was not evident from the measured AMSU-B data. We conclude that it is valid to use the two criteria in combination as a cloud filter.

While the threshold of $240 \mathrm{~K}$ for $T_{B}^{18}$ is valid for nadir looking measurements, due to limb darkening this threshold shifts to colder brightness temperatures for off-nadir looking measurements. As shown in the right plots of Fig. 1, the depression from nadir to off-nadir is approximately $7 \mathrm{~K}$.

To derive viewing angle dependent values for the $T_{B}^{18}$ threshold, we simulated clear-sky AMSU-B measurements for each instrument angle. This simulation was done with a sampled ECMWF data set (Chevallier, 2001) using the Atmospheric Radiative Transfer Simulator (ARTS) (Buehler et al., 2005). For each viewing angle, minima of $T_{B}^{18}$ for a number of $\Delta T_{B}$ intervals around the $\Delta T_{B}$ threshold were determined. The mean of these minima was taken as $T_{B}^{18}$ threshold for that viewing angle. A summary of the threshold values is given in Table 1 .

Figures similar to Fig. 1 were also generated for other latitude ranges (not shown). Overall, they look rather similar. In particular, the assumed threshold values appear to be applicable also for tropical and sub-tropical data. We make no attempt here to fine-tune the filter for these other latitudes, since the focus of the paper is on mid-latitudes.

\section{Results and discussion}

In this section we demonstrate the cloud filter using a strong ice cloud event over northern midlatitudes. We also estimate the clear-sky bias in the retrieved UTH fields due to cloud screening, and discuss the impact of surface emissions.

\subsection{Case study}

For the case study we used model fields and microwave measurements from a strong ice cloud event that occurred over the UK on 25 January 2002. The model fields are from the Met Office (UK) mesoscale model UKMES (Cullen, 1993). Profiles of pressure, temperature, relative humidity, cloud ice water content and cloud liquid water content were used to simulate AMSU-B radiances. (Incidentally, the same meteorological event was used in Buehler et al. (2007) to illustrate the measurement of a proposed submillimeter-wave cloud sensor.)

To put the results of the cloud impact in perspective, one should keep in mind the properties of the applied UTH retrieval method and its limitations. For this purpose we applied the method first on simulated clear-sky brightness temperatures. The results are displayed in Fig. 3, which shows the quantities $\mathrm{UTH}_{\mathrm{Jac}}$ and $\mathrm{UTH}_{\mathrm{Tb}}$ in different ways. The 
Table 1. Viewing angle ( $\theta$ in degrees from nadir) dependent thresholds for Ch18 brightness temperatures (in K).

\begin{tabular}{cccccccccc}
\hline$\theta$ & $T_{B}^{18}$ & $\theta$ & $T_{B}^{18}$ & $\theta$ & $T_{B}^{18}$ & $\theta$ & $T_{B}^{18}$ & $\theta$ & $T_{B}^{18}$ \\
\hline 0.55 & 240.1 & 10.45 & 239.8 & 20.35 & 239.2 & 30.25 & 238.2 & 40.15 & 236.4 \\
1.65 & 240.1 & 11.55 & 239.8 & 21.45 & 239.2 & 31.35 & 238.0 & 41.25 & 236.1 \\
2.75 & 240.1 & 12.65 & 239.7 & 22.55 & 239.1 & 32.45 & 237.8 & 42.35 & 235.8 \\
3.85 & 240.1 & 13.75 & 239.7 & 23.65 & 239.0 & 33.55 & 237.6 & 43.45 & 235.5 \\
4.95 & 240.1 & 14.85 & 239.6 & 24.75 & 238.8 & 34.65 & 237.4 & 44.55 & 235.2 \\
6.05 & 240.1 & 15.95 & 239.6 & 25.85 & 238.7 & 35.75 & 237.2 & 45.65 & 234.9 \\
7.15 & 240.1 & 17.05 & 239.5 & 26.95 & 238.6 & 36.85 & 237.0 & 46.75 & 234.4 \\
8.25 & 239.9 & 18.15 & 239.4 & 28.05 & 238.5 & 37.95 & 236.7 & 47.85 & 233.9 \\
9.35 & 239.9 & 19.25 & 239.3 & 29.15 & 238.3 & 39.05 & 236.6 & 48.95 & 233.3 \\
\hline
\end{tabular}
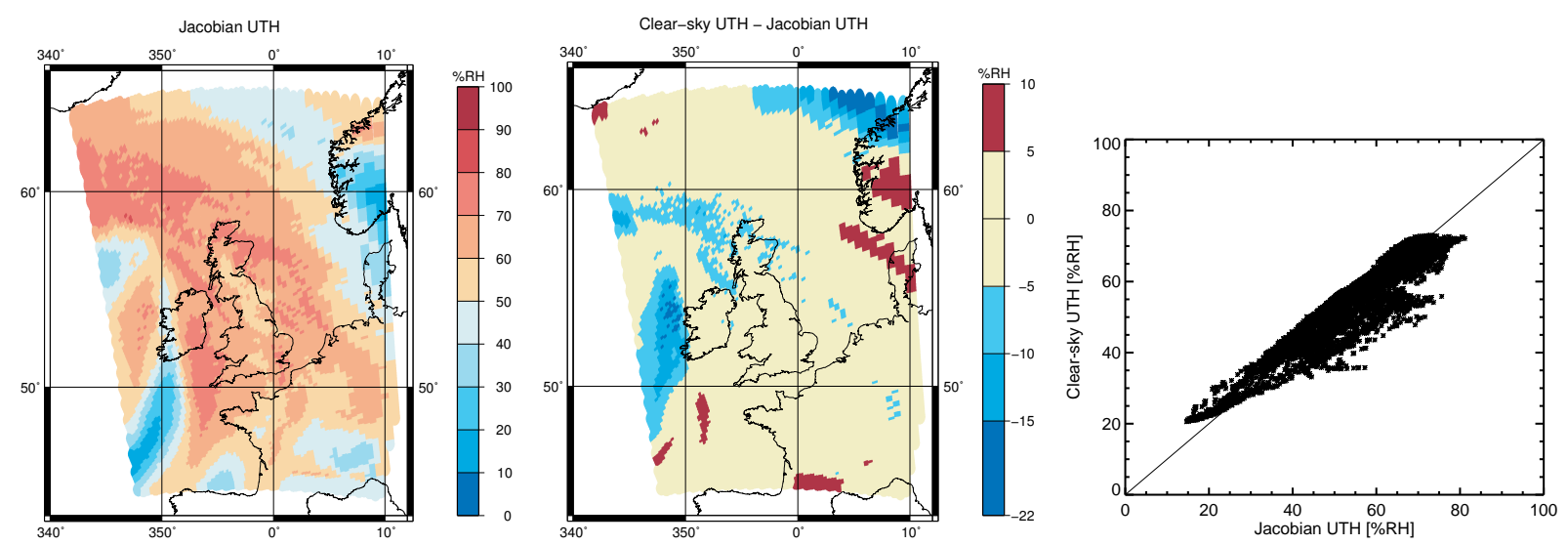

Fig. 3. A comparison between clear-sky simulated brightness temperatures converted to $\mathrm{UTH}_{\mathrm{Tb}}$ and $\mathrm{UTH}_{\mathrm{Jac}}$. Left: Model UTHJac ; middle: $\mathrm{UTH}_{\mathrm{Tb}}-\mathrm{UTH}_{\mathrm{Jac}}$; right: Scatter plot of $\mathrm{UTH}_{\mathrm{Tb}}$ versus $\mathrm{UTH}_{\mathrm{Jac}}$. Relative humidity here, as everywhere in the paper, is defined over liquid water.

quantity $\mathrm{UTH}_{\mathrm{Jac}}$ is the Jacobian weighted upper tropospheric humidity, calculated from the relative humidity profiles and the AMSU-B Jacobian (for details, see BJ). This is the "true" UTH in this context. The quantity $\mathrm{UTH}_{\mathrm{Tb}}$ is UTH calculated from the simulated brightness temperatures by applying the coefficients derived by BJ. This is the "retrieved" UTH in this context. The humidity unit used here and everywhere in this article is the relative humidity over liquid water (\% RH).

The leftmost plot of the figure shows a map of the $\mathrm{UTH}_{\mathrm{Jac}}$ field. The middle plot shows a map of $\mathrm{UTH}_{\mathrm{Tb}}-\mathrm{UTH}_{\mathrm{Jac}}$. The rightmost plot is a scatter-plot of $\mathrm{UTH}_{\mathrm{Tb}}$ versus $\mathrm{UTH}_{\mathrm{Jac}}$. The figure shows that the retrieval method works well, as most of the differences are within $\pm 5 \% \mathrm{RH}$. It is interesting to note, where the discrepancies between $\mathrm{UTH}_{\mathrm{Jac}}$ and retrieved $\mathrm{UTH}$, which are referred to as regression noise in BJ, happen. Strong differences of up to $22 \% \mathrm{RH}$ occur in areas with unusual atmospheric states, for example behind the cold front. In this area, where warm air is over-laying cold air, the temperature and humidity lapse rates are less steep than in the average state, resulting in a different relation between $\ln (\mathrm{UTH})$ and brightness temperature.
Comparing the scatter plot of $\mathrm{UTH}_{\mathrm{Tb}}$ versus $\mathrm{UTH}_{\mathrm{Jac}}$ in Fig. 3 with the similar scatter plot presented in Fig. 4 of BJ reveals, that the differences are in the same order. The map plot reveals that what appears as noise for a set of random atmospheric states, appears as area biases for a real atmospheric scenario, because neighboring atmospheric states are similar. This is the expected behavior of a regression retrieval method.

In addition to these errors from the regression method, a retrieval from real AMSU-B data will contain errors due to a possible contribution by the surface, and due to clouds. The surface effects for this scenario were assessed by repeating the simulations with different surface emissivities of 0.6 and 0.99 for over-land data. $\mathrm{UTH}_{\mathrm{Tb}}$ between the two different emissivities differs by less than $0.4 \% \mathrm{RH}$ for the investigated scenario which means that surface effects are negligible in this case.

Let us now come to the cloud impact. Figure 4 is used to discuss this. The top left plot in Fig. 4 shows the ice water path (IWP) field. The model does not provide information on the size distribution of the cloud particles or their shape and orientation. Therefore, it was assumed that 

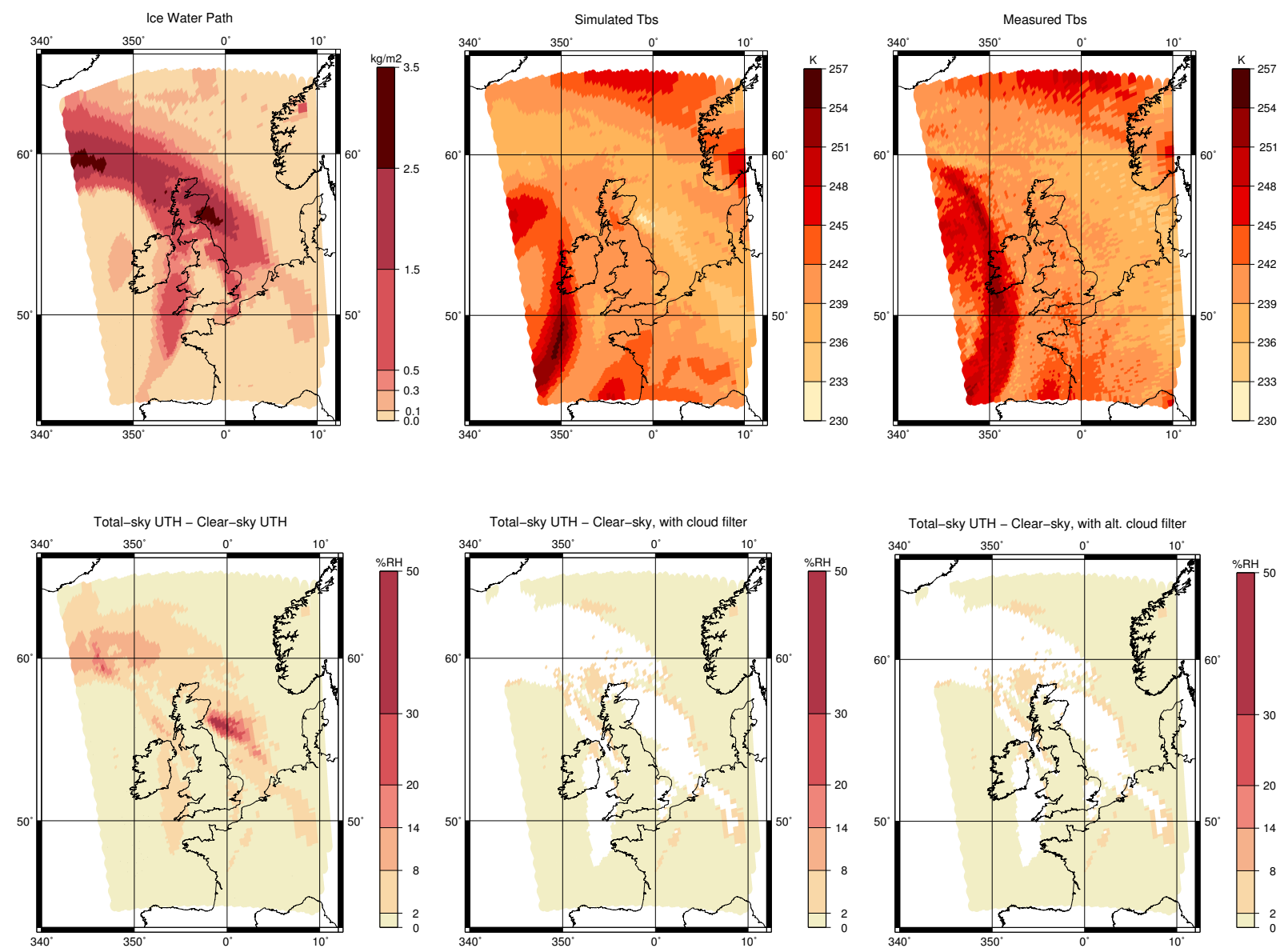

Fig. 4. Top row, left plot: mesoscale NWP model IWP field. Top row, middle plot: simulated AMSU-B Ch18 radiances (ARTS RT model simulation, based on model fields). Top row, right plot: measured AMSU-B Ch18 radiances. Bottom row, left plot: UTH difference between the full simulation and a simulation with cloud ice amount set to zero. Bottom row, middle plot: the same as in the left plot, but with applied Ch20 cloud filter. Bottom row, right plot: the same as in the middle plot, but for the Ch19 cloud filter.

all particles have a spherical shape following a size distribution according to McFarquhar and Heymsfield (1997). This parametrization was chosen out of convenience, and because it is the parametrization used for operational EOS-MLS retrievals (Wu et al., 2006).

The top middle plot in Fig. 4 shows simulated AMSU-B $\mathrm{Ch} 18$ radiances for this scene. The radiances were simulated with the Atmospheric Radiative Transfer Simulator (ARTS) (Buehler et al., 2005) using the version that can simulate scattering (Emde et al., 2004). The emissivity value over land was set to 0.95 , over ocean the emissivity model FASTEM (English and Hewison, 1998) was used. The top right plot shows measured radiances. As the two plots show, the simulation is in fair agreement with the real AMSU-B measurements, if one allows for the expected small displacements of the cloud features.

The bottom row of Fig. 4 shows the cloud induced error in UTH fields derived by applying the UTH retrieval algorithm of BJ to the simulated $\mathrm{Ch} 18$ radiances. The effect of clouds was assessed by comparing the $\mathrm{UTH}_{\mathrm{Tb}}$ (clear) for simulated clear-sky radiances to the $\mathrm{UTH}_{\mathrm{Tb}}$ (total) for simulated all-sky radiances. The difference $(\Delta \mathrm{UTH}=$ $\mathrm{UTH}_{\mathrm{Tb}}$ (total) $-\mathrm{UTH}_{\mathrm{Tb}}$ (clear)) is displayed in the bottom left plot of Fig. 4. It shows that most of the differences are below $2 \% \mathrm{RH}$. These moderate differences are caused by an ice water path below approximately $0.1 \mathrm{~kg} / \mathrm{m}^{2}$. The maximum difference reaches $50 \% \mathrm{RH}$ in a few cases with exceptionally high ice content. In those cases IWP is up to $3.5 \mathrm{~kg} / \mathrm{m}^{2}$. The bottom middle plot of Fig. 4 shows the same as the bottom left plot, but hiding the pixels that are removed by the Ch20 cloud filter. It shows that the filter indeed reliably removes the high IWP cases. The bottom right plot shows the same for the Ch19 cloud filter, which gives practically the same result. (Closer investigation of this case revealed that for this particular scene most cloudy points are removed by the $T_{B}^{18}$ threshold, which is the same in both filters, so the similarity is not surprising.)

As mentioned earlier, Ch18, which is used for the retrievals, is sensitive to high ice clouds. The micro-physics of these clouds and the amount of ice in clouds in gen- 
eral are still uncertain (Pruppacher and Klett, 1997; Jakob, 2002; Quante and Starr, 2002). However, based on current in-situ measurements and model predictions, one can make assumptions on lower and upper boundaries of cloud ice content. In-situ observations have reported several kilograms of IWP for extreme events (A. J. Heymsfield, personal communication). Sreerekha (2005) shows that the IWP in global ECMWF ERA-40 data is at maximum close to $1 \mathrm{~kg} / \mathrm{m}^{2}$. In our case study the maximum IWP is about $3.5 \mathrm{~kg} / \mathrm{m}^{2}$. This illustrates that the maximum ice content depends strongly on the averaging scale, since clouds with extreme ice content typically have a small horizontal scale. One can assume that an IWP of $3.5 \mathrm{~kg} / \mathrm{m}^{2}$ is close to the upper limit of the amount of ice found in midlatitude clouds on the approximately $15 \mathrm{~km}$ horizontal scale of AMSU-B. The maximum cloud signal (cloudy radiances minus clear-sky radiances) on simulated brightness temperature in our case study is approximately $8 \mathrm{~K}$. This is consistent with Greenwald and Christopher (2002, Fig. 7) who report only very few cases of cloud signals exceeding $8 \mathrm{~K}$ outside the tropics.

\subsection{Clear-sky bias}

In this section we analyze the bias introduced by cloud clearance. We also estimate lower and upper limits of cloud impact on a derived UTH climatology.

Cloud contamination will lead to a brightness temperature reduction, and hence to a high (wet) bias in the UTH climatology. The usual practice in such cases is to filter out the cloud contaminated data before the UTH retrieval. The problem with that approach is that clouds are associated with high values of relative humidity. Therefore, removing the cloud contaminated data may introduce a dry bias (clear-sky bias) in the retrieved UTH climatology. To study this aspect of cloud filtering in our case we made a comparison of retrieved UTH with and without applying the cloud filter.

The mean UTH values in the scene for the different data products investigated are summarized in Table $2 . \mathrm{UTH}_{\mathrm{Jac}}$ is the Jacobian weighted UTH. UTH $\mathrm{Tb}_{\mathrm{Tb}}$ (clear) is retrieved from simulated clear-sky radiances. $\mathrm{UTH}_{\mathrm{Tb}}$ (total) is retrieved from simulated total-sky radiances. $\mathrm{UTH}_{\mathrm{Tb}}(\mathrm{Ch} 20$ filter) and $\mathrm{UTH}_{\mathrm{Tb}}(\mathrm{Ch} 19$ filter) are retrieved from simulated total-sky radiances after cloud filtering. We define the cloud wet bias as $\mathrm{UTH}_{\mathrm{Tb}}^{\text {total }}-\mathrm{UTH}_{\mathrm{Tb}}^{\text {clear }}$ and the cloud filtering dry bias as $\mathrm{UTH}_{\mathrm{Tb}}^{\text {cloud-cleared }}-\mathrm{UTH}_{\mathrm{Tb}}^{\text {clear }}$.

The mean UTH in the scene with cloud filtering is $54 \% \mathrm{RH}$, approximately $3 \% \mathrm{RH}$ less than the true $\mathrm{UTH}_{\mathrm{Tb}}$ (clear) for the entire scene. One could have expected the bias to be even larger, but as explained in Soden and Lanzante (1996), the retrieved UTH corresponds to an average relative humidity over a thick layer of the atmosphere (roughly between 500 and $200 \mathrm{hPa}$, for details see BJ), while the vertical extent of high clouds is much less than this. Therefore in the presence of such clouds, it is improbable
Table 2. Mean and median UTH in the scene for different kinds of data. All values are in \% RH.

\begin{tabular}{lccccc}
\hline Data & mean & median & std & $\min$ & $\max$ \\
\hline $\mathrm{UTH}_{\mathrm{Jac}}$ & 58.04 & 60.36 & 11.99 & 14.66 & 81.13 \\
$\mathrm{UTH}_{\mathrm{Tb}}$ (clear) & 57.16 & 59.78 & 10.86 & 20.56 & 73.04 \\
$\mathrm{UTH}_{\mathrm{Tb}}$ (total) & 59.07 & 60.59 & 12.78 & 20.56 & 99.33 \\
$\mathrm{UTH}_{\mathrm{Tb}}($ Ch20 filter $)$ & 53.98 & 56.05 & 10.51 & 20.56 & 68.37 \\
$\mathrm{UTH}_{\mathrm{Tb}}($ Ch19 filter $)$ & 53.99 & 56.05 & 10.51 & 20.56 & 68.37 \\
\hline
\end{tabular}

that the whole layer, to which the UTH is sensitive, will be saturated. (See also Fig. 7 and its discussion in Sect. 3.4.)

There is little difference between $\mathrm{UTH}_{\mathrm{Jac}}$ and $\mathrm{UTH}_{\mathrm{Tb}}$ (clear). The mean for $\mathrm{UTH}_{\mathrm{Tb}}$ (total) reveals that clouds indeed introduce a $2 \% \mathrm{RH}$ high bias relative to $\mathrm{UTH}_{\mathrm{Tb}}$ (clear). On the other hand, the mean for $\mathrm{UTH}_{\mathrm{Tb}}(\mathrm{Ch} 20$ filter) reveals that cloud filtering introduces a $-3 \% \mathrm{RH}$ low bias relative to $\mathrm{UTH}_{\mathrm{Tb}}$ (clear). Both the cloud bias and the cloud filtering bias are modest, with the true UTH value roughly in the middle of the two. The reason for the modest cloud impact is that cases with very high IWP values are rare, even in the extreme scene investigated. If the median instead of the mean is used, clouds introduce a smaller (1\% RH) wet bias.

This result at first sight appears to be in contradiction to the conclusion of Greenwald and Christopher (2002) that precipitating cold clouds bias UTH by $18 \%$ RH on average. However, the average there refers only to the overcast pixels, not all pixels as in our case.

Figure 5 further demonstrates that the bias introduced by both clouds and cloud filtering is moderate. It shows for a seasonal mean UTH climatology the difference between UTH derived from all available AMSU-B data and UTH derived from data which passed the two different cloud filters described in the previous section. Both filters perform very similarly. As expected, a positive difference occurs in the upper tropospheric wet zones (compare, e.g., Soden and Bretherton (1996, Fig. 6)). The cloud-filtered UTH climatology in these areas is drier than the unfiltered one, by up to approximately $6 \% \mathrm{RH}$. As explained above, the cloud filtered climatology is expected to be drier than the true one, whereas the unfiltered climatology is expected to be wetter than the true one.

\subsection{Surface effect on UTH}

In very dry atmospheric conditions, measurements from AMSU-B Ch18 can be contaminated by surface emission. As described above in Sect. 2, this situation leads also to Ch18 being warmer than Ch20, and thus triggers the cloud filter.

Figure 6 shows cloud and surface effects on UTH data. It is the same as Fig. 5, but the data used are for the northernhemispheric winter season. As the middle plot shows, in this 


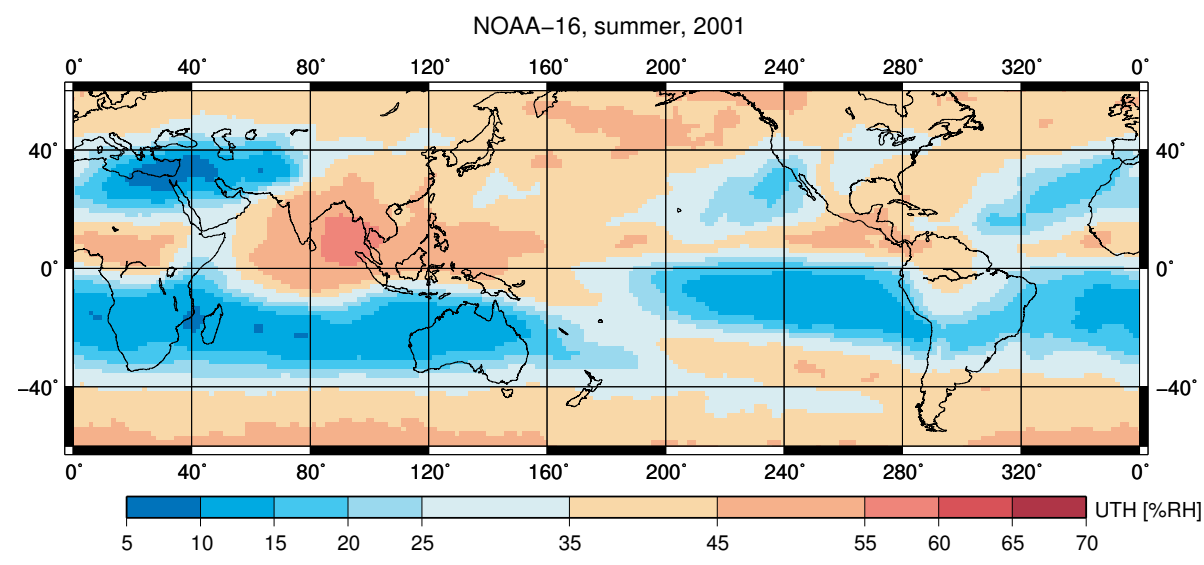

Total - Clear Sky, NOAA-16, summer, 2001

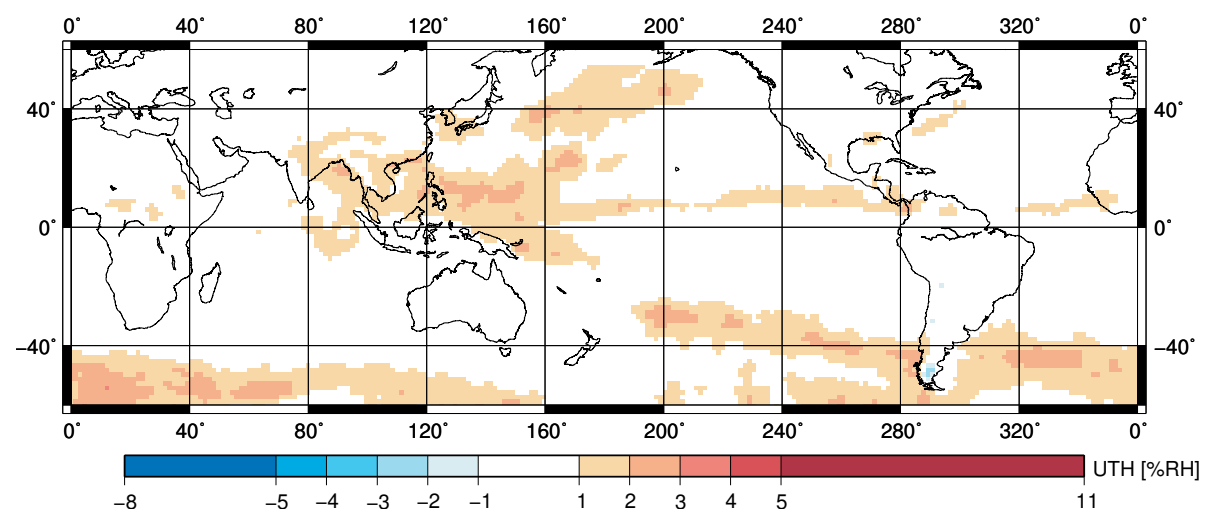

Total - Clear Sky, NOAA-16, summer, 2001, alt. cloud filter

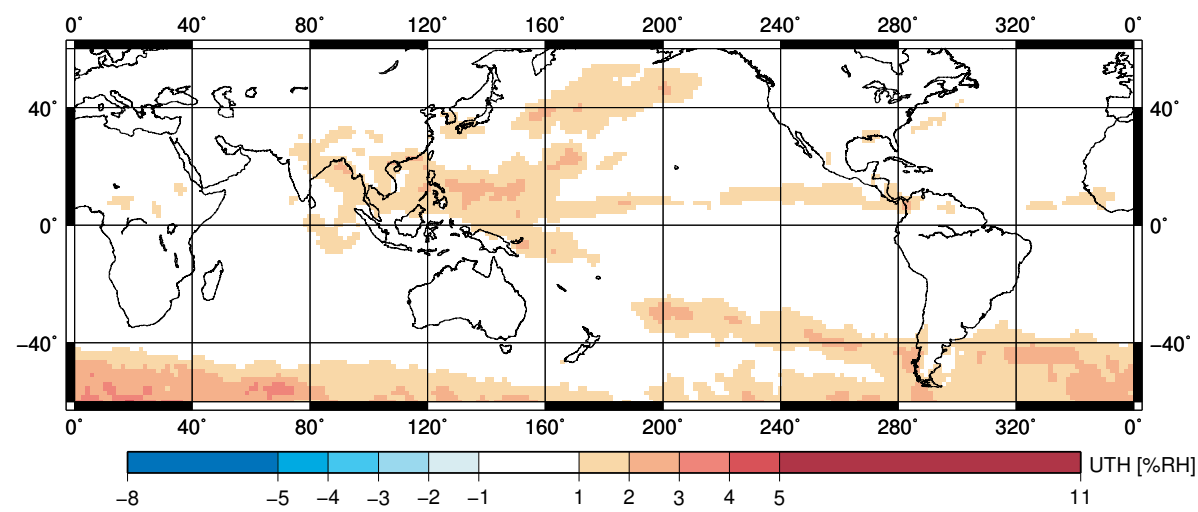

Fig. 5. Top: Seasonal UTH climatology derived from $183.31 \pm 1.00 \mathrm{GHz}$ microwave data from the NOAA 16 satellite between June 2001 and August 2001. This plot is without any cloud filtering. Middle: Difference between UTH derived from all available data and UTH derived from data which passed the Ch20 cloud filter described in the previous section. Minimum, maximum, and mean of the UTH difference in the middle plot are $-3.9,3.9$ and $0.6 \pm 0.6 \% \mathrm{RH}$, respectively. Bottom: Same as middle plot, but for Ch19 filter. Minimum, maximum, and mean of the UTH difference in the bottom plot are $-0.4,4.6,0.6 \pm 0.7 \% \mathrm{RH}$, respectively.

case the difference $\mathrm{UTH}_{\mathrm{Tb}}$ (total) $-\mathrm{UTH}_{\mathrm{Tb}}(\mathrm{Ch} 20$ filter) can reach values as low as $-7 \% \mathrm{RH}$ and as high as $+10 \% \mathrm{RH}$.

These high differences are due to surface effects and can be divided into two cases. In the first case, the surface is radiometrically cold. Measured cold brightness temperatures will be interpreted as high UTH, and will thus lead to a wet bias (red areas). An example of this case is the Himalaya.
In general, this case occurs for elevated, ice covered regions such as Antarctica and Greenland. In the second case, the surface is radiometrically warm. Measured warm brightness temperatures will be interpreted as low UTH, and will thus lead to a dry bias (blue areas). This case occurs for desert and snow covered areas with high emissivity. 

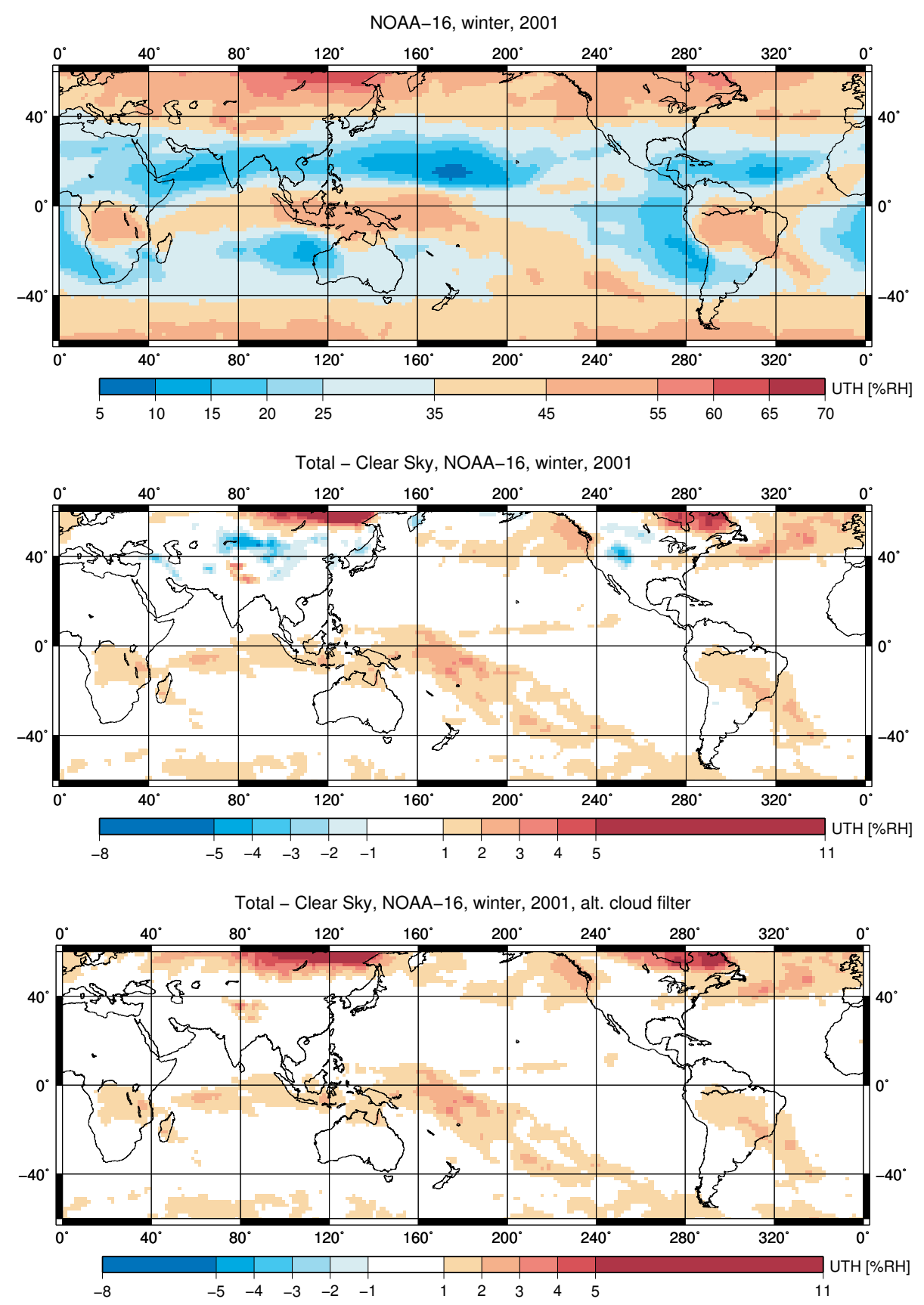

Fig. 6. Cloud and surface effects on AMSU-B data. This is the same as Fig. 5, but the data used are from December 2001 to February 2002. Minimum, maximum and mean of the UTH difference in the middle plot with Ch20 filter are $-7.3,10.7$ and $0.6 \pm 1.0 \%$ RH, respectively. minimum, maximum, and mean of the UTH difference in the bottom plot with Ch19 filter are $-1.4,10.9,0.7 \pm 1.0 \% \mathrm{RH}$, respectively.

It should be noted that the middle plot in Fig. 6 exaggerates the surface problem in the retrieved UTH values somewhat, since the filter uses both $\mathrm{Ch} 20$, which is sensitive to lower altitudes, and Ch18, whereas the UTH retrieval uses only Ch18.

This becomes clearer when one compares to the UTH difference for the Ch19 filter (bottom plot in Fig. 6). It does not produce the surface artifacts at midlatitudes that the $\mathrm{Ch} 20$ filter produces.

\subsection{Midlatitude cloud database study}

Rydberg et al. (2007) used radar data to create a database for cloud ice retrieval from microwave to sub-mm measurements. The database contains midlatitude cloud cases, along with associated radiances. The cloud microphysical properties are randomized, but adjusted so that their radar reflectivity matches CLOUDNET radar data from the stations Chilbolton (UK), Palaiseau (France), and Cabauw (Nether- 
Table 3. Mean and median UTH in the cloud database for different kinds of data. All values are in \% RH.

\begin{tabular}{lccccc}
\hline Data & mean & median & std & min & $\max$ \\
\hline $\mathrm{UTH}_{\mathrm{Jac}}$ & 42.76 & 41.54 & 17.48 & 5.28 & 96.58 \\
$\mathrm{UTH}_{\mathrm{Tb}}$ (clear) & 43.40 & 42.80 & 15.12 & 5.30 & 99.73 \\
$\mathrm{UTH}_{\mathrm{Tb}}$ (total) & 44.17 & 43.19 & 16.03 & 5.30 & 99.99 \\
$\mathrm{UTH}_{\mathrm{Tb}}$ (Ch20 filter) & 43.89 & 42.98 & 15.76 & 5.30 & 97.48 \\
$\mathrm{UTH}_{\mathrm{Tb}}$ (Ch19 filter) & 43.96 & 43.04 & 15.80 & 5.30 & 97.48 \\
\hline
\end{tabular}

lands). Radiances are calculated with the ARTS model. The database used radar data from the years 2003 to 2004 and contains approximately 200000 cases. It is important to note that the database was constructed to contain representative statistics of humidity and cloud parameters for midlatitudes. All radar data were used, so the dataset contains also many clear-sky cases, and the distribution of cloudy versus clear cases comes directly from the radar data. The looking angle for these simulations is fixed at 45 degrees.

Since the original purpose of the database was to simulate the performance of a future sub-millimeter wave cloud sensor (Jimenez et al., 2007), it is not optimal for AMSU, but has a cold bias relative to dedicated AMSU simulations. The reason for the bias is a combination of slightly different observation frequency, different definitions of brightness temperature, and approximations taken in the RT simulation. The database also assumes a blackbody surface (emissivity equals 1.0). Despite these shortcomings, the database can be used to test the cloud filter. To account for the cold bias, the Ch18 threshold for the filter was set to $230 \mathrm{~K}$, instead of its nominal value of $235 \mathrm{~K}$ for the 45 degree looking angle.

The exercises performed in the case study were extended to this database. As for the case study, three kinds of mean $\mathrm{UTH}$ were investigated. $\mathrm{UTH}_{\mathrm{Jac}}$ is the Jacobian weighted UTH. $\mathrm{UTH}_{\mathrm{Tb}}$ (total) is retrieved from simulated total-sky radiances. $\mathrm{UTH}_{\mathrm{Tb}}(\mathrm{Ch} 20$ filter $)$ is retrieved from simulated total-sky radiances after cloud filtering. All values are given in Table 3.

As expected, $\mathrm{UTH}_{\mathrm{Tb}}$ (total) is the largest of all, but the differences beween all the different values are small. $\mathrm{UTH}_{\mathrm{Tb}}$ (total) is only approximately $0.8 \% \mathrm{RH}$ "wetter" than $\mathrm{UTH}_{\mathrm{Tb}}$ (clear) in the mean, and only approximately $0.4 \% \mathrm{RH}$ "wetter" in the median. The cloud filtered values are only $0.5 \% \mathrm{RH}$ away from $\mathrm{UTH}_{\mathrm{Tb}}$ (clear) in the mean, and only $0.2 \% \mathrm{RH}$ away in the median.

It should be noted that the exact numbers here depend on the exact thresholds for the cloud filter. For example, raising the Ch18 threshold makes the filtered UTH "drier". The important point here is that overall the cloud bias is modest, and it is further reduced by approximately $50 \%$ by the cloud filter. The results show that the conclusions from the case study hold in general for midlatitude conditions, with the difference that the cloud filtering is not introducing a dry bias here, but even the filtered data still have a slight moist bias. This is most likely due to the fact that the filter thresholds are not chosen perfectly for this dataset, although a rough adjustment was made, as explained above.

Figure 7 shows in more detail how the cloud filters work on the database cases. It shows histograms of some important parameters, separately for the cases that were classified clear (thick line) and the cases that were classified cloudy (thin line). The two rows show figures for the Ch20 filter (top) and the Ch19 filter (bottom), which look very similar.

The leftmost plots show histograms of IWP, confirming that the filters indeed remove most of the cases where a large amount of cloud ice is present. The plots show also that the filters are not perfect, as even the "clear" data contains still approximately $10 \%$ of cases with IWP exceeding $10 \mathrm{~g} / \mathrm{m}^{2}$ and $3 \%$ of cases with IWP exceeding $100 \mathrm{~g} / \mathrm{m}^{2}$. On the other hand, some clear cases are erroneously marked as cloudy, approximately $0.3 \%$ for the $\mathrm{Ch} 20$ filter and approximately $0.5 \%$ for the Ch19 filter. These cases have IWP below $1 \mathrm{mg} / \mathrm{m}^{2}$, although they are classified as cloudy.

The middle plots of Fig. 7 show histograms of the cloud induced UTH error $\left(\triangle \mathrm{UTH}=\mathrm{UTH}_{\mathrm{Tb}}\right.$ (total $)-\mathrm{UTH}_{\mathrm{Tb}}($ clear $)$ ). They confirm that the cloud filters drastically reduces this error. The cloud cases that remain in the "clear" class (i.e., those cases that are missed by the filters) lead to $\triangle$ UTH not larger than $22 \% \mathrm{RH}$, whereas otherwise $\Delta \mathrm{UTH}$ can be up to $74 \% \mathrm{RH}$. (Note that the plots do not show data with $\triangle \mathrm{UTH}$ exceeding $40 \%$ RH.)

The rightmost plots in Fig. 7 show histograms of humidity itself $\left(\mathrm{UTH}_{\mathrm{Jac}}\right)$. They confirm that the cloudy cases indeed are associated with higher UTH values than the clear cases. The maximum of the PDF for the cloudy class is at approximately $50 \%$ RH. (Note that this relative humidity, as everywhere in this article, is over liquid water. If one uses relative humidity over ice, the maximum of the PDF is at approximately $65 \% \mathrm{RH}_{i}$.)

The plot suggests yet another strategy how to deal with cloudy data, that is, to set all UTH values for cloudy scenes to $50 \% \mathrm{RH}$. For the midlatitude cloud dataset, this strategy leads to a mean UTH which is indeed close to the true $\mathrm{UTH}_{\mathrm{Tb}}$ (clear) (by definition). The problem with this strategy is that it can not be readily generalized to global data, since we do not at present have statistics similar to the ones in Fig. 7 for global data.

\section{Conclusions}

In this study a method for filtering high and heavily laden ice clouds in AMSU-B microwave data was developed. The method combines two existing methods. One is thresholding brightness temperatures from Ch18 (Greenwald and Christopher, 2002). The other one is thresholding brightness temperature differences, either between Ch20 and Ch18 (Burns et al., 1997), or between Ch19 and Ch18. The method also 

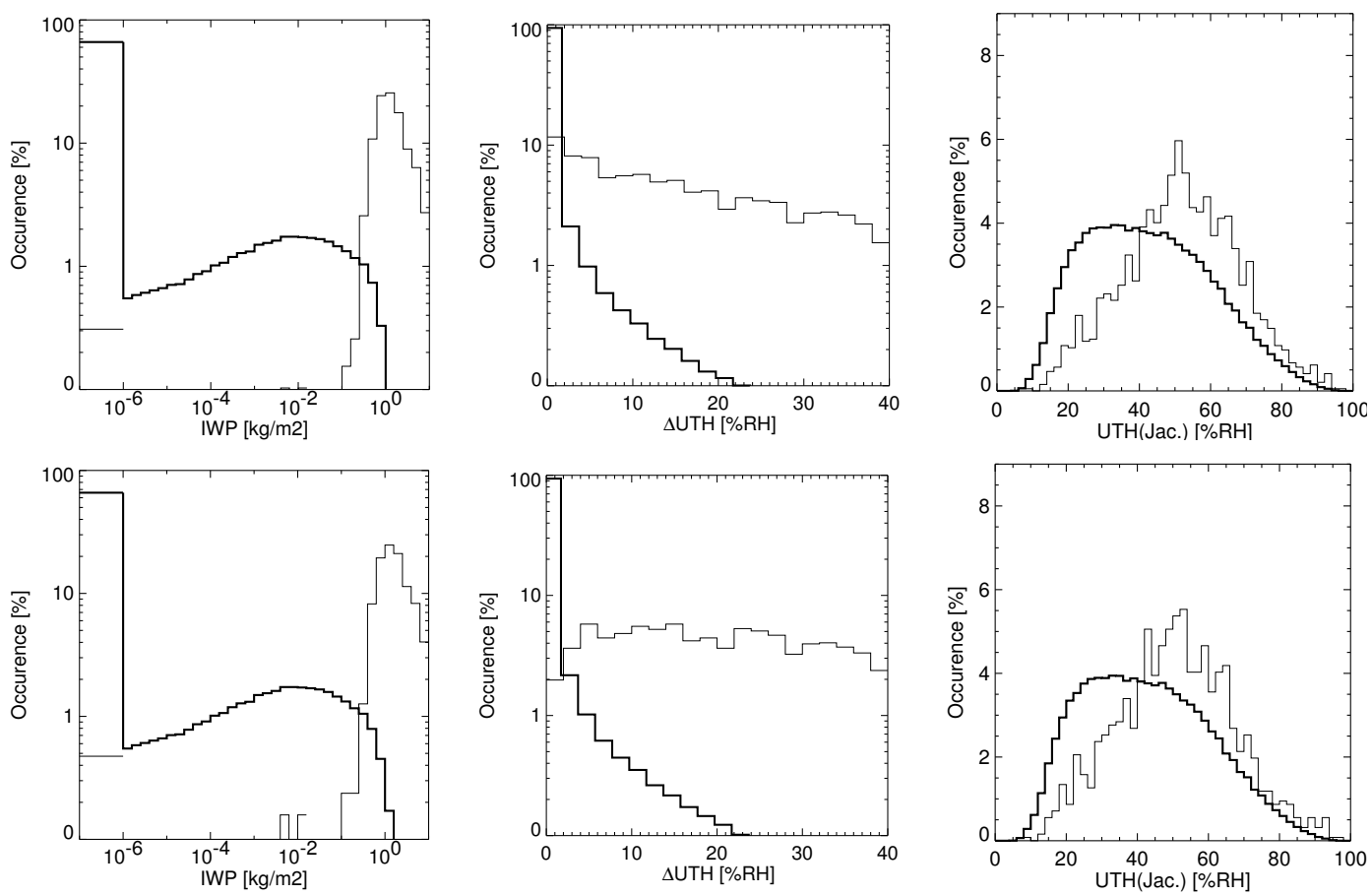

Fig. 7. Histograms of some key parameters for cases that were classified clear (thick line) and cases that were classified cloudy (thin line). The top row is for the Ch20 cloud filter, the bottom row for the Ch19 cloud filter. Left: IWP; middle: $\Delta \mathrm{UTH}_{\text {; }}$ right: $\mathrm{UTH}_{\mathrm{Jac}}$. The bin sizes of $\mathrm{UTH}_{\mathrm{Jac}}$ and $\triangle \mathrm{UTH}$ are $2 \% \mathrm{RH}$. The bin size of IWP follows the logarithmic scale of the x-axis. Note that the leftmost bin of the IWP histogram contains all data between 0 and $10^{-6} \mathrm{~kg} / \mathrm{m}^{2}$. The "clear" class contains approximately 180000 cases, the "cloudy" class approximately 2000 cases.

takes into account the viewing geometry of the instrument, by using viewing angle dependent $\mathrm{Ch} 18$ threshold values.

The robustness of both filter variants was demonstrated in a case study of a particularly intense ice cloud event over the UK, and by applying the filter to a database of midlatitude cloud cases.

These exercises show that both filter variants are well suited to filter out cloud contaminated data from AMSU-B. It should be possible to use the same technique also for other similar instruments.

The UTH retrieval method of Buehler and John (2005) was confirmed to be well suited for deriving a UTH climatology from AMSU-B Ch18 data. Also, some new light was shed on the known limitations of this method. It was demonstrated, that the error that is referred to as regression noise in the earlier paper, is due to atmospheric profiles that are far from the mean of the profiles used to derive regression coefficients, and is thus spatially highly correlated.

Furthermore, the impact of ice clouds on UTH area mean values derived from satellite microwave data was estimated. For the case study with a heavily laden ice cloud, the scene averaged UTH value for the unfiltered data is $2 \% \mathrm{RH}$ too wet, the cloud filtered UTH value is $-3 \%$ RH too dry (both relative to the true scene averaged UTH value, retrieved from simulated radiances where the clouds have been turned off). For the radar-based midlatitude cloud and clear-sky case database, the unfiltered mean UTH is $0.8 \% \mathrm{RH}$ too wet, the cloud filtered mean UTH is $0.4 \% \mathrm{RH}$ too wet. Both cloud- and cloud filtering bias are smaller in this case, as expected. These numbers are representative for general midlatitude conditions, since the case database was constructed to have realistic statistics. We conclude that, for midlatitudes, the best UTH retrieval strategy is to derive UTH with the cloud filter, but retain also the unfiltered values, so that the difference between the two can be used as an estimate of the cloud induced uncertainty.

The same strategy is likely to be also applicable to the tropics, but it is harder to prove this, since the radar-based database is at present only available for midlatitudes. However, a first look at global AMSU UTH data reveals that in the tropics the difference between total-sky and clear-sky UTH is also less than 3\% RH. Thus, the difference between total-sky and clear-sky UTH values should give a useful cloud error estimate also there.

Besides the cloud issue, it was shown that the proposed filter also removes surface contaminated data, which can occur in certain areas in the winter season. The impact of surface contamination on UTH is comparable to the cloud impact, but slightly larger. Also, the impact can be a low or high bias, depending on the surface conditions. In areas and seasons where surface contamination occurs the data should only be used with caution. 
The filter variant using Ch19 instead of Ch20 to calculate brightness temperature differences was shown to remove fewer false surface influence cases. (The cases where Ch20 already sees the surface, but Ch18 and Ch19 do not.) Since both filter variants otherwise perform very similarly, the Ch19 variant is the recommended one.

Acknowledgements. We acknowledge J. Miao for his work on the $2 \mathrm{D}$ cloud filter. We thank the UK MetOffice for providing us with the mesoscale model outputs. Also, we thank the ARTS radiative transfer community. Many thanks to Nathalie Courcoux for providing us with RTTOV simulations. This study was partly funded by the German Federal Ministry of Education and Research (BMBF), within the AFO2000 project UTH-MOS, grant 07ATC04. It is a contribution to COST Action 723 "Data Exploitation and Modeling for the Upper Troposphere and Lower Stratosphere".

Edited by: W. T. Sturges

\section{References}

Adler, R. F., Mack, R. A., Prasad, N., Hakkarinen, I. M., and Yeh, H.-Y.: Aircraft Microwave Observations and Simulations of Deep Convection from 18 to $183 \mathrm{GHz}$. Part I: Observations, J. Atmos. Ocean Technol., 7, 377-391, 1990.

Anderson, G. P., Clough, S. A., Kneizys, F. X., Chetwynd, J. H., and Shettle, E. P.: AFGL atmospheric constituent profiles (0120 km), Tech. rep., AFGL, TR-86-0110, 1986.

Buehler, S. A. and John, V. O.: A Simple Method to Relate Microwave Radiances to Upper Tropospheric Humidity, J. Geophys. Res., 110, D02110, doi:10.1029/2004JD005111, 2005.

Buehler, S. A., Eriksson, P., Kuhn, T., von Engeln, A., and Verdes, C.: ARTS, the Atmospheric Radiative Transfer Simulator, J. Quant. Spectrosc. Radiat. Transfer, 91, 65-93, doi:10.1016/j. jqsrt.2004.05.051, 2005.

Buehler, S. A., Jimenez, C., Evans, K. F., Eriksson, P., Rydberg, B., Heymsfield, A. J., Stubenrauch, C., Lohmann, U., Emde, C., John, V. O., Sreerekha, T., and Davis, C.: A concept for a satellite mission to measure cloud ice water path and ice particle size, Q. J. Roy. Meteor. Soc., in press, preprint available on http://www. sat.ltu.se/publications, 2007.

Burns, B. A., Wu, X., and Diak, G. R.: Effects of Precipitation and Cloud Ice on Brightness Temperatures in AMSU Moisture Channels, IEEE T. Geosci. Remote, 35, 1429-1437, 1997.

Chevallier, F.: Sampled databases of 60-level atmospheric profiles from the ECMWF analysis, Tech. rep., ECMWF, EUMETSAT SAF program research report no. 4 , available at: www.metoffice. com/research/interproj/nwpsaf/rtm/profiles.pdf, 2001.

Cullen, M. J. P.: The Unified Forecast/Climate Model, Meteorol. Mag., 122, 81-94, 1993.

Emde, C., Buehler, S. A., Davis, C., Eriksson, P., Sreerekha, T. R., and Teichmann, C.: A Polarized Discrete Ordinate Scattering Model for Simulations of Limb and Nadir Longwave Measurements in 1D/3D Spherical Atmospheres, J. Geophys. Res., 109, D24207, doi:10.1029/2004JD005140, 2004.

English, S. J. and Hewison, T. J.: Fast generic millimeter-wave emissivity model, in: Proc. SPIE Vol. 3503, Microwave Remote Sensing of the Atmosphere and Environment, Tadahiro Hayasaka; Dong L. Wu; Ya-Qiu Jin; Jing-shan Jiang; Eds., edited by: Hayasaka, T., Wu, D. L., Jin, Y.-Q., and Jiang, J.-S., 288300, 1998.

Greenwald, T. J. and Christopher, S. A.: Effect of Cold Clouds on Satellite Measurements Near 183 GHz, J. Geophys. Res., 107, 4170, doi:10.1029/2000JD0002580, 2002.

Hong, G., Heygster, G., Miao, J., and Kunzi, K.: Detection of tropical deep convective clouds from AMSU-B water vapor channels measurements, J. Geophys. Res., 110, D05205, doi: 10.1029/2004JD004949, 2005.

Jakob, C.: Ice clouds in numerical weather prediction models: Progress, problems, and prospects, in: Cirrus, edited by: Lynch, D. K., Sassen, K., Starr, D. O., and Stephens, G., Oxford University Press, New York, 327-345, 2002.

Jimenez, C., Buehler, S. A., Rydberg, B., Eriksson, P., and Evans, K. F.: Performance simulations for a submillimetre wave cloud ice satellite instrument, Q. J. Roy. Meteor. Soc., in press, preprint available on http://www.sat.ltu.se/publications, 2007.

Labrot, T., Lavanant, L., Whyte, K., Atkinson, N., and Brunel, P.: AAPP Documentation Scientific Description, version 6.0, document NWPSAF-MF-UD-001, Tech. rep., NWP SAF, Satellite Application Facility for Numerical Weather Prediction, http://www.metoffice.gov.uk/research/interproj/nwpsaf/ aapp/NWPSAF-MF-UD-001_Science.pdf, 2006.

McFarquhar, G. M. and Heymsfield, A. J.: Parameterization of Tropical Cirrus Ice Crystal Size Distribution and Implications for Radiative Transfer: Results from CEPEX, J. Atmos. Sci., 54, 2187-2200, 1997.

Pruppacher, H. R. and Klett, J. D.: Microphysics of Clouds and Precipitation, Kluwer Academic Publishers, The Netherlands, reprinted with corrections 2000, 1997.

Quante, M. and Starr, D.: Dynamical processes in cirrus clouds: A Review of Observational Results, in: Cirrus, edited by: Lynch, D. K., Sassen, K., Starr, D. O., and Stephens, G., Oxford University Press, New York, 346-374, 2002.

Rydberg, B., Eriksson, P., and Buehler, S. A.: Prediction of cloud ice signatures in sub-mm emission spectra by means of groundbased radar and in-situ microphysical data, Q. J. Roy. Meteor. Soc., in press, preprint available on http://www.sat.ltu.se/ publications, 2007.

Saunders, R.: RTTOV-7 Users guide, http://www.metoffice.gov.uk/ research/interproj/nwpsaf/rtm/rttov7_svr.pdf, 2002.

Saunders, R. W., Hewison, T. J., Stringer, S. J., and Atkinson, N. C.: The Radiometric Characterization of AMSU-B, IEEE T. Microw. Theory, 43, 760-771, 1995.

Soden, B. J. and Bretherton, F. P.: Interpretation of TOVS water vapor radiances in terms of layer-average relative humidities: Method and climatology for the upper, middle, and lower troposphere, J. Geophys. Res., 101, 9333-9344, doi:10.1029/ 96JD00280, 1996.

Soden, B. J. and Lanzante, J. R.: An Assessment of Satellite and Radiosonde Climatologies of Upper-Tropospheric Water Vapor, J. Climate, 9, 1235-1250, 1996.

Sreerekha, T. R.: Impact of clouds on microwave remote sensing, Ph.D. thesis, University of Bremen, 2005.

Wu, D. L., Jiang, J. H., and Davis, C.: EOS MLS Cloud Ice Measurements and Cloudy-Sky Radiative Transfer Model, IEEE T. Geosci. Remote, 44, 1156-1165, 2006. 